\title{
Finite Element Analysis on Lining Structure of Diversion Tunnel in a Hydropower Station
}

\author{
Heng Zhou ${ }^{1,2 *}$, Xiaofan An ${ }^{1,2}$, Peng Huang ${ }^{1,2}$, Xuguang Chen ${ }^{3}$, Shengjie $\mathrm{Di}^{1,2}, \mathrm{Xi} \mathrm{Lu}^{1,2}$, Longwei Yang ${ }^{1,2}$ \\ ${ }^{1}$ Northwest Engineering Corporation Limited, Power China, 710065 Xi'an, Shaanxi, China \\ ${ }^{2}$ High Slope and Geological Hazard Research \& Management Branch, National Energy and Hydropower Engineering Technology R\&D \\ Center, 710065 Xi' an, Shaanxi, China \\ ${ }^{3}$ Ocean University of China, 266100, Qingdao, Shandong, China
}

\begin{abstract}
Aiming at the high internal and external water pressure tunnels built in unfavorable geological bodies, this study proposes a novel type of composite support structure in which steel plates are poured inside concrete linings. Compared with traditional structures, it has the advantages of higher tensile strength, better crack resistance, and impermeability. Taking the diversion tunnel of a hydropower station as an example, based on linear and non-linear finite element simulations, mechanical properties of the steelconcrete composite lining structure for a hydraulic tunnel in soft surrounding rocks are analyzed. On this basis, the concrete crack control under this supporting condition is verified. Research results can provide a reference for the selection of reasonable steel plate thicknesses and reinforcement types in design.
\end{abstract}

\section{Introduction}

Hydraulic tunnels generally adopt a composite lining structure, with rock bolts and sprayed concrete as the initial flexible support, and reinforced concrete as the secondary rigid lining [1]. The traditional reinforced concrete lining has the defects of large thickness, complicated process, and poor crack resistance, so it is prone to cracking, water leakage, and other diseases in long-term operation. Composite structures of steel plate and concrete is a new type of tunnel lining structure, which has the characteristics of excellent tensile performance of steel plates, and high compressive strength of concrete [2]. In its construction, the technology of prefabricating steel plates in factories, assembling and pouring concrete on site is adopted. The lining has the advantages of small thickness, high strength, easy operation, and maintenance [3-5].

A hydropower station locates on the mainstream of the Nan'er River in central Laos, which is the third stage of cascade development from downstream to upwards. The control drainage area above the dam site is $3913 \mathrm{~km}^{2}$, the annual runoff is 3.47 billion $\mathrm{m}^{3}$, and the annual average flow is $110 \mathrm{~m}^{3} / \mathrm{s}$. The project layout form is CFRD + left bank spillway + right bank diversion system (including about $11 \mathrm{~km}$ long diversion tunnels, upstream surge tanks, ground powerhouses, etc.). Among them, the pressure diversion tunnel has a flow rate of $178.92 \mathrm{~m} 3 / \mathrm{s}$, which connects to the upstream surge tank through a turn on the plane. The tunnel traverses the $3 \#$ ravine with a buried depth of $120 \sim 160 \mathrm{~m}$ and a circular section diameter of $9.3 \mathrm{~m}$. The upstream side of the $3 \#$ ravine is a granite section, and the downstream side is a limestone section. The granite in lithological contact zones is strongly weathered, with a full-strength weathering depth of up to $160 \mathrm{~m}$; limestone karst is developed, and the surface densely covers with sinkholes. The groundwater in excavated granite walls is dripping and flowing. The limestone section is rich in groundwater and has good connectivity with surface water. Therefore, water inrush occurred in several places during the construction process (see Fig. 1 for the geological profile). Due to the extremely poor geological conditions of the tunnel and high-water pressures, considering the safety and cost of the project, the tunnel adopts a new type of lining with steel plates placed in the middle of reinforced concrete linings.

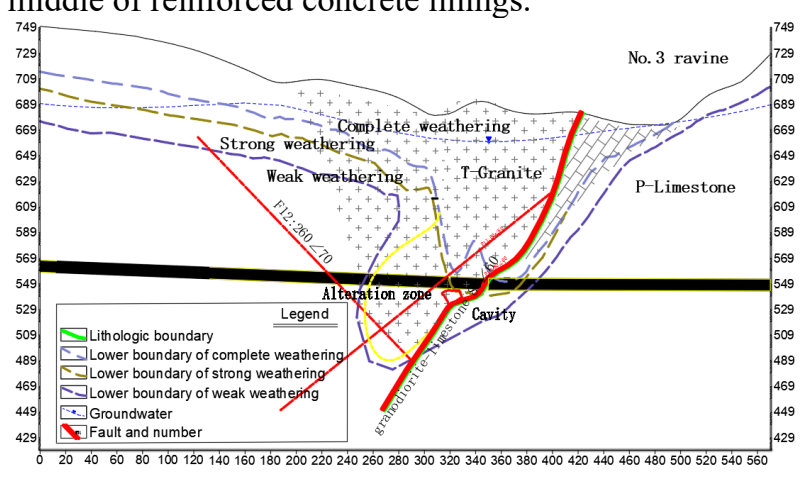

Fig. 1. Geological profile of the tunnel traverses $3 \#$ ravine

Using linear and non-linear finite element simulation methods, this study takes the diversion tunnel as an example, the mechanical properties of steel-concrete composite lining structures under the conditions of high internal-external water pressures in soft rocks are comparatively analysed. Meanwhile, concrete crack control under this support scheme is verified.

\footnotetext{
*Corresponding author: 1728@nwh.cn
} 
Furthermore, a reasonable plate thickness and reinforcement type for design selection are put forward.

\section{Methodology}

\subsection{Reinforcement calculation}

Reinforcement calculation of concrete linings adopts a linear elastic finite element method based on the ANSYS platform, and the tensile bearing capacity of the lining section is shown in Fig. 2. The axial tensile force $\mathrm{N}$ acts on the small eccentric tension member between resultant points $A_{s}$ and $A_{s}^{\prime}$ of the steel, the tensile bearing capacity at the normal section is,

$$
\begin{aligned}
& N e \leq \frac{1}{\gamma_{d}} f_{y} A_{s}^{\prime}\left(h_{0}-a_{s}^{\prime}\right) \\
& N e^{\prime} \leq \frac{1}{\gamma_{d}} f_{y} A_{s}\left(h_{0}^{\prime}-a_{s}\right)
\end{aligned}
$$

where, $A_{s}$ and $A_{s}^{\prime}$ are the cross-sectional areas of the longitudinal steel bars arranged on the side close to and away from the axial tension; $e$ and $e^{\prime}$ are the distances from the axial tension to the resultant points $A_{s}$ and $A_{s}^{\prime}$ of reinforcement.
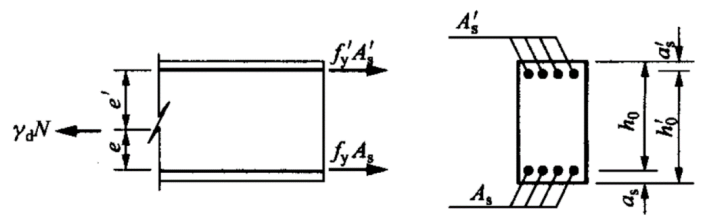

Fig. 2. Calculation of tensile bearing capacity at normal section of small eccentric tension member

\subsection{Crack checking}

Due to the complexity of reinforced concrete materials and load effects, various types of concrete constitutive relations, failure criteria, and interaction models between steel bars and concrete, etc., are the mathematicalmechanical models established on the basis of physical tests and some simplified assumptions, which are basically consistent with the test results. Different assumptions make the finite element software adopt various models in nonlinear analysis of reinforced concrete.

ABAQUS is one of the most powerful nonlinear finite element analysis tools in the world. It provides concrete elastoplastic fracture damage models and reinforcement elements. To simulate the characteristic that the unloading stiffness of concrete decreases with the increase of damage, the model introduces a damage index into concrete models and reduces the elastic stiffness matrix of concretes. Therefore, based on linear elastic analysis of lining reinforcement, a more applicable nonlinear finite element method is selected for the calculation of concrete crack width in this study [6-7].
According to the regulations on crack control check for non-member system structure: the circular reinforced concrete lining is calculated by nonlinear finite element, and the crack width is controlled according to the stress of steel bars. The maximum allowable crack width in limit state design of hydraulic tunnels is: long-term combination $0.25 \mathrm{~mm}$ (when the thickness of protective layers is $50 \mathrm{~mm}$, the corresponding steel stress is 147.5MPa), short-term combination $0.30 \mathrm{~mm}$ (when the thickness of protective layers is $50 \mathrm{~mm}$, the corresponding steel stress is $160 \mathrm{MPa}$ ).

The width of surface cracks can be controlled by limiting the element stress of the first layer of tension steel. Under the action of standard combination, element stress $\sigma_{x}$ of the first layer of tensile steel on the surface should meet the following requirements:

$$
\sigma_{s k s} \leq \sigma_{s p s}
$$

where, $\sigma_{s k s}$ is the element stress of tensile steels in the first layer calculated by finite elements of reinforced concrete under the standard combination action; $\sigma_{s p s}$ is the stress limit of tensile steel elements with surface cracks on non-member structures. $\sigma_{s p s}$ should be selected according to the crack width and the thickness of protective layers: when the crack width is controlled at $0.1 \mathrm{~mm} \sim 0.3 \mathrm{~mm}$ and the thickness of protective layers is $50 \mathrm{~mm}, \sigma_{s p s}$ should not exceed $110 \mathrm{~N} / \mathrm{mm}^{2} \sim 160 \mathrm{~N} / \mathrm{mm}^{2}$; when the thickness of protective layers is $100 \mathrm{~mm}$, it should not exceed $80 \mathrm{~N} / \mathrm{mm}^{2} \sim 140 \mathrm{~N} / \mathrm{mm}^{2}$.

\section{Modelling scheme and parameter selection}

The reservoir water level during normal operation is $723 \mathrm{~m}$, the pressure head of internal and external water in modeling is $200 \mathrm{~m}$ and $110 \mathrm{~m}$ respectively. Internal and external pressures are considered based on surface forces when calculating lining structures; the internal pressure includes hydrostatic pressures and water hammer pressures.

The steel plate-concrete composite lining structure is shown in Fig. 3. To compare the mechanical properties of the structure when a steel plate is located at different positions in concrete, the following four modeling schemes are selected in this study:

Scheme 1: The steel plate is not considered, and the thickness of lining concrete is $110 \mathrm{~cm}$;

Scheme 2: The steel plate locates in the middle of lining concrete (the inner and outer concrete thicknesses are $50 \mathrm{~cm}$ and $60 \mathrm{~cm}$ respectively), considering the action of steel plate and inner concrete;

Scheme 3: The steel plate locates in the middle of lining concrete (the inner and outer concrete thicknesses are $50 \mathrm{~cm}$ and $60 \mathrm{~cm}$ respectively), considering the action of the steel plate and outer concrete;

Option 4: The steel plate is located in the middle of the lining concrete (the inner and outer concrete thicknesses are $40 \mathrm{~cm}$ and $70 \mathrm{~cm}$ respectively), considering the action of the steel plate and outer concrete. 
Fig. 1 reveals that the tunnel passes through the $3 \#$ ravine with stake numbers $\mathrm{T} 6+680 \sim \mathrm{T} 6+710$ to expose the most unfavorable geological conditions. Based on this section as a standard, the physical and mechanical parameters of surrounding rocks and supporting structure in numerical modeling are selected as shown in Tables $1-4$.

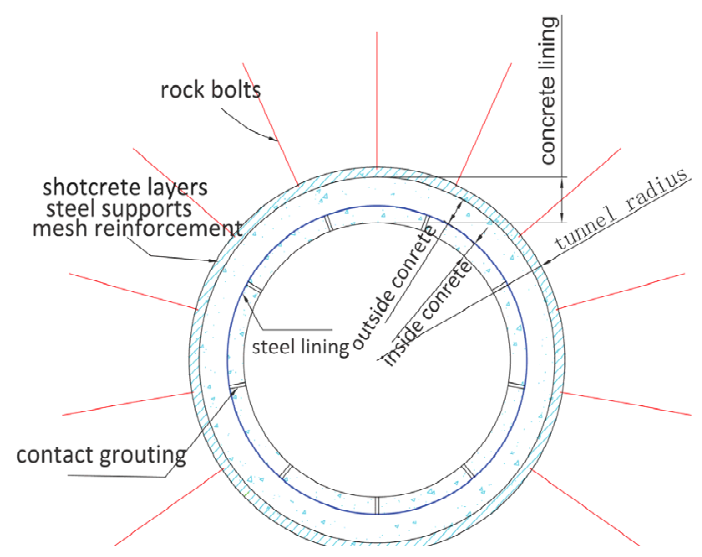

Fig. 3. Schematic diagram of steel plate-concrete lining supporting structure in circular tunnels

Table 1. Physical and mechanical parameters of rocks.

\begin{tabular}{|c|c|}
\hline $\begin{array}{c}\text { Stake number } \\
/ \mathrm{m}\end{array}$ & $\mathrm{T} 6+680 \sim \mathrm{T} 6+710$ \\
\hline Rock category & $\mathrm{V}$ \\
\hline Saturation density $/ \mathrm{g} / \mathrm{cm}^{3}$ & 2.18 \\
\hline Uniaxial compressive strength $/ \mathrm{MPa}$ & 10 \\
\hline Deformation modulus $/ \mathrm{MPa}$ & 350 \\
\hline $\begin{array}{c}\text { Unit elastic resistance coefficient } \\
/ \mathrm{MPa} / \mathrm{cm}\end{array}$ & 2.5 \\
\hline Poisson's ratio & 0.45 \\
\hline Cohesion $/ \mathrm{MPa}$ & 0.05 \\
\hline Friction coefficient & 0.36 \\
\hline
\end{tabular}

Table 2. Physical and mechanical parameters of concrete.

\begin{tabular}{|c|c|}
\hline Strength grade & C25 \\
\hline Bulk density $/ \mathrm{kN} / \mathrm{m}^{3}$ & 24 \\
\hline $\begin{array}{c}\text { Design value of axial } \\
\text { compressive strength } / \mathrm{MPa}\end{array}$ & 11.9 \\
\hline $\begin{array}{c}\text { Design value of axial tensile } \\
\text { strength } / \mathrm{MPa}\end{array}$ & 1.27 \\
\hline Elastic modulus $/ \mathrm{MPa}$ & 28000 \\
\hline Poisson's ratio & 0.167 \\
\hline
\end{tabular}

Table 3. Reinforcement strength and elastic modulus.

\begin{tabular}{|c|c|}
\hline Type of reinforcement & HRB400 \\
\hline Strength standard value $/ \mathrm{MPa}$ & 400 \\
\hline Strength design value $/ \mathrm{MPa}$ & 360 \\
\hline Elastic modulus /MPa & $2.0 \times 10^{5}$ \\
\hline
\end{tabular}

Note: Tensile design value of steel bar for axial tension and small eccentric tension members is $300 \mathrm{MPa}$.

Table 4. Design value of steel plate strength.

\begin{tabular}{|c|c|}
\hline Steel grade (standard) & Q345R (GB 713) \\
\hline Thickness $/ \mathrm{mm}$ & 14 \\
\hline Bulk density $/ \mathrm{kN} / \mathrm{m}^{3}$ & 78.5 \\
\hline Yield strength $/ \mathrm{MPa}$ & 345 \\
\hline Tensile strength/MPa & 510 \\
\hline Tensile/ Compression/ Bending & 310 \\
\hline
\end{tabular}

\begin{tabular}{|c|c|}
\hline$/ \mathrm{MPa}$ & \\
\hline Shear $/ \mathrm{MPa}$ & 180 \\
\hline End pressure capacity /MPa & 435 \\
\hline
\end{tabular}

\section{Result analysis}

Fig. 4 shows the circumferential stress cloud diagram of the lining under normal operation conditions and different steel plate layouts. Without considering the concrete reinforcement and steel plate (Scheme 1), the maximum hoop stress of the tunnel lining is $4.86 \mathrm{MPa}$ (Fig. 4a), which is much greater than the concrete axial tensile strength. Considering the combined bearing of steel plate and lining (Scheme 2), the hoop stress of concrete is reduced compared with that without considering combined bearing (Fig. 4b). Since concrete is regarded as a linear elastic material in the calculation of reinforcement, the coordinated deformation of concrete and steel plates makes the concrete stress exceed its limit tensile strength. However, the Mises stress of the steel plate is not large, and the maximum value is $27.9 \mathrm{MPa}$. If the model considers the effects of steel plate and outer concrete, as shown in Scheme 3 (the combined bearing of outer concrete and steel plate, without considering the effect of inner concrete), the hoop stress of concrete $(8.01 \mathrm{MPa})$ increases significantly compared to when the inner concrete is considered. Meanwhile, the Mises stress of the steel plate also increases obviously, with a maximum value of 60.73MPa (Fig. 5), and the radial deformation does not exceed $1.86 \mathrm{~mm}$.
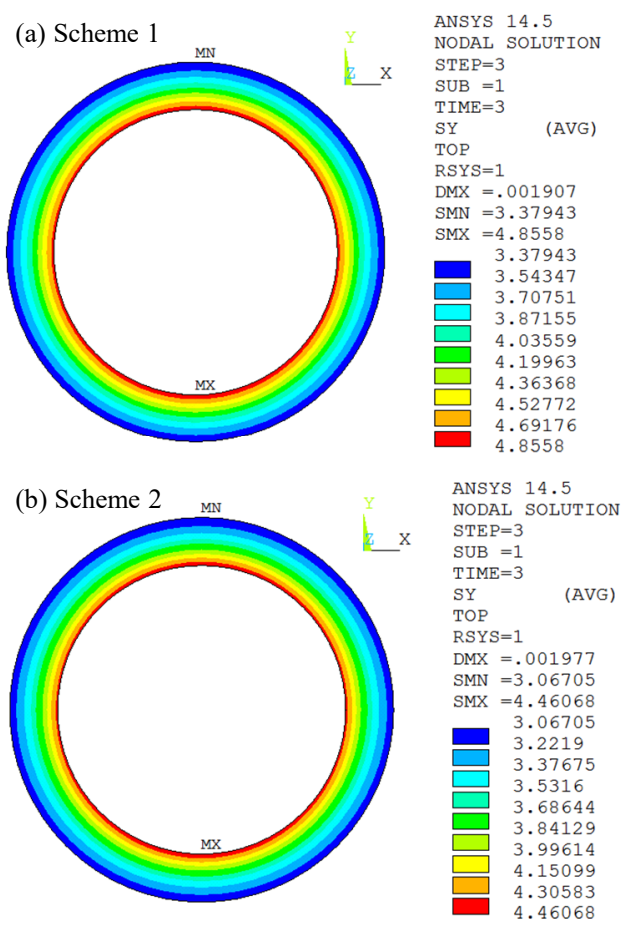

Fig. 4. Circumferential stress cloud diagram of lining in each scheme (MPa)

In Scheme 4, the steel plate divides the lining concrete into $40 \mathrm{~cm}$ and $70 \mathrm{~cm}$ thickness of inner and outer concrete. The interaction between the steel plate and the outer concrete is considered in the model. 
Compared with Scheme 3, due to the increase in the thickness of the outer concrete, the hoop stress of the lining and the Mises stress of the steel plate is significantly reduced to $6.89 \mathrm{MPa}$ and $53.89 \mathrm{MPa}$ (Fig. $5)$, respectively. The radial deformation does not exceed $1.81 \mathrm{~mm}$.

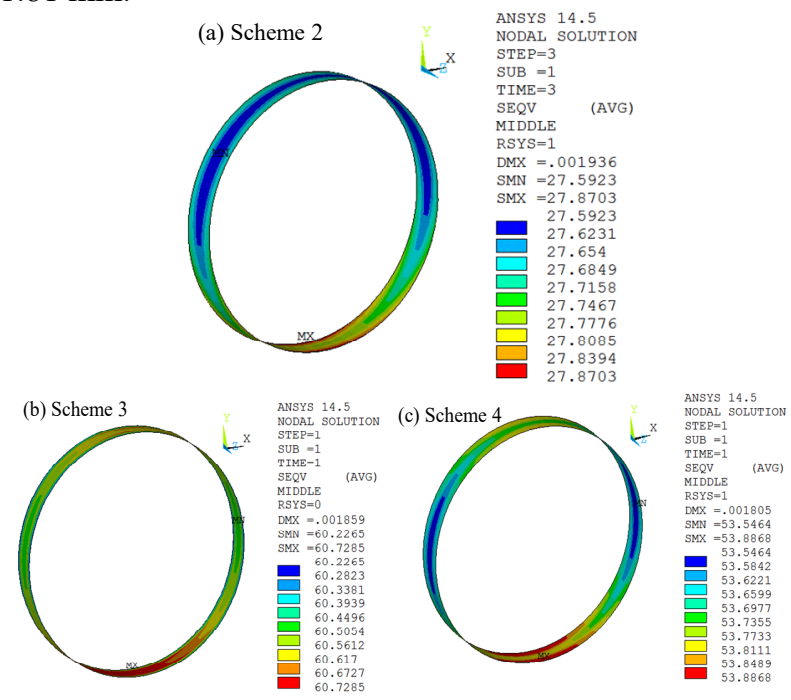

Fig. 5. Mises stress cloud diagram of steel plate in each scheme (MPa)

A steel plate is arranged in the middle of lining concrete as an anti-seepage structure. In the most unfavorable case, that is, when inner concrete cracks (internal water seepage at this time), the cracks develop in outer concrete are checked. Simulation selects the thickness of $40 \mathrm{~cm}$ inner concrete and $70 \mathrm{~cm}$ outer concrete (Scheme 4), so that internal water pressures are borne by steel plates, outer concrete, and surrounding rocks. Because it is difficult to set four layers of steel bars in the outer $70 \mathrm{~cm}$ thick concrete, the reinforcement with two layers of the inner side and one layer of the outer side is considered in calculation, see Table 5. In this condition, the maximum tensile stress of the steel bar is $134 \mathrm{MPa}$ (Fig. 6), which is less than the maximum allowable stress of a steel bar demonstrated in section 2.2. Therefore, the design solution meets the requirements for crack control.

Table 5. Reinforcement scheme and stress (protective layer thickness 50mm).

\begin{tabular}{|c|c|c|}
\hline $\begin{array}{c}\text { Reinforcement } \\
\text { recommend }\end{array}$ & $\begin{array}{c}\text { Maximum } \\
\text { stress of steel } \\
\text { bar } \\
/ \mathrm{MPa}\end{array}$ & $\begin{array}{c}\text { Limit } \\
\text { strength of } \\
\text { steel bar } \\
/ \mathrm{MPa}\end{array}$ \\
\hline $\begin{array}{c}\text { Two layers of } \\
\text { \$32@150 at inner side, } \\
\text { one layer of } \$ 32 @ 150 \\
\text { at outer side }\end{array}$ & 134 & 147.5 \\
\hline
\end{tabular}

Note: Spacing of $150 \mathrm{~mm}$ means that 7 steel bars are arranged at $1 \mathrm{~m}$. Net spacing of each layer of steel bars is $100 \mathrm{~mm}$.
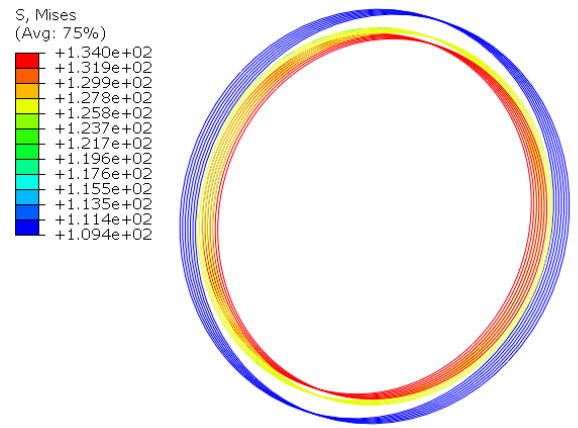

Fig. 6. Mises stress cloud diagram of steel bars used for lining crack checking $(\mathrm{MPa})$

\section{Conclusion}

Considering the requirements of anti-seepage and anticracking properties for hydraulic tunnels, a novel form of steel-concrete composite support is proposed. The result of finite element simulations based on a diversion tunnel of a hydropower station shows that, the installation of steel plates in concrete linings can not only achieve the effect of anti-seepage, but also share the tensile stress generated by high internal water pressures on lining structure to a certain extent. In addition, to ensure that the overall thickness of a lining remains unchanged, the increase of outer concrete thickness can significantly reduce the tensile stress in the lining. For this tunnel, steel-concrete support with inner and outer concrete thicknesses of $40 \mathrm{~cm}$ and $70 \mathrm{~cm}$ is selected. Considering the most unfavorable conditions for inner concrete cracking, the outer concrete can meet crack control requirements when two layers of $\$ 32 @ 150$ on the inner side and one layer of $\$ 32 @ 150$ on the outer side are set for the reinforcement.

\section{Acknowledgments}

Financial support for this research was provided by the major science and technology project of Northwest Engineering Corporation Limited, Power China. The authors would like to thank our colleagues for their help in technical support.

\section{References}

1. S. Alan, S. Hossein, H.A. Mousa. Tunn. (2021)Predicting long-term stability of tunnels considering rock mass weathering and deterioration of primary support. Undergr. Sp. Tech. 107, 103670.

2. Y.H. Wang, J.G. Nie, H.S. Hu. (2016) Stability of steel-concrete composite beams with full openings in concrete flange. Mater. Struct. 49, 12.

3. M. Shams, M.A. Saadeghvaziri. (1997)State of the art of concrete-filled steel tubular columns. ACI Struct. J. 94, 51.

4. N.E. Shanrnugam, B. Lakshmi. (2001)State of the art report on steel-concrete composite columns. J Constr. Steel Res.57, 10. 
5. J.S. KANG. (2013)Structural effects of concrete lining for concrete-lined corrugated steel pipes. Struct. Infrastruct E. 9, 2 .

6. E.S. Mohammd, E.S. Arturo, L. Jia-liang, F.L. Debra, A. Salam, M. Patrick. (2012)Structural mechanics characterization of steel intermeshed connection using nonlinear finite element analysis. Eng. Struct. 238.

7. M. Neuner, M. Schreter, P. Gamnitzer, G Hofstetter. (2012)On discrepancies between time-dependent nonlinear 3D and 2D finite element simulations of deep tunnel advance: A numerical study on the Brenner Base Tunnel. Comput. Geotech. 119, 103355. 